\title{
VENEREAL DISEASES IN THE BRITISH COLONIES*
}

BY

\section{A. M. WILSON RAE}

The problem of venereal disease in the colonial territories is one of considerable magnitude and of some complexity. This is readily understandable if we consider the vast extent of the colonial empire, scattered throughout the five continents and composed of many peoples at different levels of development-some living in comparative isolation and others in ever closer association with alien races.

I do not intend to present you with a series of figures showing the incidence of the disease in different colonies, for they would not in effect convey any real information. The compilation of true vital statistics is in its infancy in many of these territories, except perhaps for the larger centres of population, and it is, therefore, impossible to give a general picture with any claim to actual truth. Again, if we take one colony where there are only three hundred doctors to look after the needs of a population more than half that of England and Wales, it is obvious that no completely accurate picture of disease incidence is possible.

The problem is no new one although it has been aggravated in recent years by developments in transport and by the impact of two wars. In the early years of the 20th century, the seriousness of the venereal disease situation in one colony was directly responsible for the creation of its modern medical services. In Uganda, the work of the Medical Department in the early days largely consisted of attention to the European staff, African troops, and Government officials, and little attention was directed by the Government to the health needs of the natives as a whole. In the early 1900 s the ravages of syphilis among the Bugandas necessitated an official enquiry, and Colonel Lambkin of the R.A.M.C. was appointed to report on the prevalence of V.D. and to concert measures for checking its ravages. His report, presented in 1908, showed that the incidence of syphilis in certain areas was almost 90 per cent. He recommended among other things

\footnotetext{
* Read to the M.S.S.V.D. on March 30, 1951.
}

the establishment of treatment rooms under medical subordinates in localities within easy reach of all patients. These centres, established by a commission of three officers of the R.A.M.C., became the nucleus of the present medical services. A Venereal Diseases Hospital was set up at Mulago, and it was only in 1923, when some control had been established and it was realized that all human ills should be treated at one and the same time, that this V.D. Hospital became the General Native Hospital for the district. It was also found in the early days that for an efficient anti-venereal diseases campaign the primary essential was the training of local assistants. From this early beginning the Makerere Medical School has resulted. This is the only case I know of real altruism on the part of the spirochaete!

There are five sets of conditions in which the venereal diseases, especially gonorrhoea and syphilis, are particularly apt to be prevalent :

(1) The larger seaports, such as Hong Kong, Singapore, and the West Indian and West African ports.

(2) The larger towns and industrial centres to which labour is attracted from the hinterland. The young men from the villages and rural areas are drawn by the promise of financial rewards in the mines and industrial ventures, and travel many hundreds of miles seeking employment. They usually leave behind them not only their wives and children, but more important, the tribal discipline and traditions and the self-respect that goes with them. They find the greatest difficulty in orientating themselves to a new and somewhat terrifying civilization. They lose their old faith and time does not allow of its replacement by other ideals. Much depends on the organization of the new environment, and it is a fact that in the better regulated mine compounds and industrial lines a great deal is done for them, but in far too many cases they find themselves living in slum conditions where they 
fall victims only too readily to the wiles of prostitutes with consequent high risk of infection. This is unfortunately not the whole story, because the young men returning to their villages too often carry back infection into areas previously comparatively free of venereal disease. This separation of the young male from his wife and family is possibly the greatest single cause of infectiona condition which was apparent to us in Europe during the recent wars. This was a temporary condition in war but unfortunately in large areas of Africa it is a continuing factor.

(3) Communities, such as those in some of the West Indian Islands, where conditions permit an illegitimate birthrate far in excess of the legitimate.

(4) Communities in which social customs and conditions entail promiscuity, as in the Masai tribe in East Africa where the gonococcal rate at one time was eight times higher than in the neighbouring Kikuyu tribe.

(5) Primitive communities where venereal disease is not associated with the sexual act. This is not so amazing as it might appear, particularly in backward areas where urinary schistosomiasis with its dramatic symptoms is prevalent.

\section{Distribution}

The true history of venereal disease invasion in the colonies is unknown. We do know that in parts of East Africa syphilis is not a recent innovation, while in other regions the more primitive type is seen, thus presenting an interesting clinical problem which would well repay study. The rates of incidence vary greatly from colony to colony, and though these rates may in themselves be inaccurate and are almost certainly under-estimations, the divergence is nevertheless a true one. Developments in transport are rapidly changing the geographical disease pattern. Two colonies situated almost side by side showed until very recently entirely differing pictures. In the northern area of the one, which had for years been the end-point of caravan routes, syphilis accounted for almost one-third of hospital admissions, yet in the northern area of the other the disease was seldom if ever seen. This picture is being rapidly changed almost solely as the result of outside contact by development of roads and motor transport, and syphilis is making considerable inroads. Here the real blame lies with the lorry drivers. The question of the relationship of syphilis to yaws is a subject too large to be dealt with in this cursory review. Whether yaws is a primitive and tropical form of syphilis is a debatable point, and I mention it only to call your attention to the fact that syphilis does not exist amongst the Polynesians in Fiji, Tonga, and Samoa, where a very high incidence of yaws occurs (the other inhabitants of the Islands-Europeans, Indians, and Chinese are not, however, immune). On the other hand, in large areas of Africa where yaws is equally prevalent syphilis exists side by side with framboesia. The relationship between bejel, yaws, and syphilis has still to be clarified, and a full study of the problem will, I am convinced, produce results both illuminating and practical.

\section{Treatment}

The outlook has recently been entirely altered by the production of the new antibiotics. A serious obstacle in the treatment of any disease condition in the tropics is the difficulty of ensuring continuity of attendance, and only when we can give short courses with satisfactory results shall we surmount this. In treating yaws in the old days we found that in many hospitals our return rate of patients after the second injection was as low as 3 per cent. and only when we could send dressers into the villages did we obtain a reasonable proportion of cures. I feel convinced that in the larger rural areas we must rely on mass injection campaigns with the primary object of rendering patients noninfective. Follow-up to ensure individual cure in syphilis can be undertaken by the creation of static centres, but the primary object must be to stop infection. Backward peoples are quick to appreciate results and they readily come in for treatment. The one-dose method with procaine penicillin for gonorrhoea is being largely used in some territories. There is, of course, the risk of suppression of signs of concurrent syphilis, and it would be wise to stress the importance of repeated examination after the apparent cure of gonorrhoea, but it is more than doubtful if this would produce results among the primitive peoples. Serologically the complication of the presence of yaws in the community presents difficulties. In the towns every endeavour must be made to provide full and adequate treatment for all, as otherwise the returning labourer carries infection far and wide into areas where the prevalence is still low.

\section{Control}

This most difficult problem is in the main nonmedical. It entails the raising of social and economic standards and necessitates action by all sections of the community apart altogether from the Medical Departments. Eradication of slum conditions, guidance and help for workers in industrial undertakings, appreciation of the effects of detribalization, and education in its truest sense to build up 
individual self-respect and collective dignity, are essential requisites. It is of the first importance to encourage the men to bring their families with them to the towns, and for industry to provide suitable accommodation.

When social and economic conditions are good a healthy community will result; where they are not, alcoholism and venereal disease will undoubtedly grow and flourish.

On the medical side provision for adequate treatment is the essential factor, and this entails a staff fully trained and equipped, and the provision of treatment centres close to the people and staffed whenever possible by the local peoples themselves. Pari-passu with this should be the building up of a preventive service which will work by educative and propaganda measures - though these will be of little value unless the efficacy of treatment is first assured.

Propaganda must take into account the psychology of the different peoples. To use only the arguments which prove successful in Europe is to court failure, but an understanding of the desire for and love of children in the tropics will give a lead to the type of propaganda likely to be successful.

\section{Conditions in the Far East}

It would be impossible, in the time available, to consider the situation as it exists throughout the colonial empire, but perhaps a brief description of the position in the Far East might be of interest. These territories were for some years under Japanese domination-perhaps neglect would be a truer term-and the Medical Departments had an incredibly heavy task in recreating healthy conditions of life and treating the mass of disease conditions left as the aftermath of occupation. That we now have a healthier population and a lower morbidity rate speaks highly for the work of the doctors and nurses in the Far East and this is the more creditable as the majority of the workers had themselves for years suffered the privations and miseries of prison camps.

Hong Kong.-The position in Hong Kong is extremely difficult. In the absence of effective immigration control, the free services offered are largely taken up by patients who are not residents of the colony and have no real claim to them. Consequently it is difficult to judge adequately the results of treatment. Again, extreme poverty, gross overcrowding, and ignorance are important factors militating against any appreciable reduction of the disease, and the greatest difficulty is experienced in tracing contacts, as the majority of addresses are only temporary. The widespread faith of the masses in Chinese herbal treatment creates a further difficulty, but with the growing appreciation of the value of penicillin, there is a definite swing of opinion in favour of western medicine.

There are five Government clinics, three on the Island and two in Kowloon. Attached to one of the female clinics is a small hospital of sixteen beds with four cots, and there are some beds allocated to V.D. treatment in the Queen Mary Hospital. These clinics are open during normal office hours and there are four evening clinics a week for office workers. Compulsory powers for examination and treatment of alleged sources of infection were in force in 1946 and 1947, but they were in fact never used, and even after the proclamation was repealed, the majority of traced contacts attended without resistance.

A considerable number of seamen are treated in the Hong Kong clinics ; these are well known along the South China coast so that seamen come in for treatment from Macao, Canton, Swatow, and other near-by ports.

Malaya.-Here the incidence of venereal disease is less than before the war. This is the more satisfactory when we consider that nothing was done to combat the infection during the Japanese occupation and that moral standards declined markedly during that period. The number of cases seen in 1945 and 1946 was much above the pre-war average, but a steady decline has occurred since 1947. That this decline is a true one is proved by comparative studies in places where treatment facilities have been constant for many years.

The causes of decline are social and medical. The most important social cause is the alteration in the pattern of the population. In the Indian and Chinese populations, there are no longer large numbers of immigrant males. The sex ratio is more nearly normal in the young adult groups and the proportion of males who are married and have their wives living with them in Malaya is increasing steadily.

The medical reasons are the improvement in methods of treatment and the efficacy of modern drugs. The most important single factor is the rapidity with which gonococcal infections subside and cease to be infectious under treatment. The incidence of syphilis is declining, though less rapidly. Women are coming in for treatment more readily, both those of the prostitute class and married women infected by their husbands.

The administrative aim is the total elimination of venereal disease by extension of facilities of treatment and educational measures. The difficulties are the usual ones of lack of trained 
staff and finance. The shortage of money does not affect the provision of drugs and equipmentthese are in ample supply for the existing personnel, but it does affect expansion of staff, both medical and ancillary. Plans to deal with this aspect of the problem, however, are well advanced.

Singapore.-Here active steps were taken immediately after the liberation, and as early as October, 1945, special clinics and beds were provided. Since then a steady expansion of the scheme has gone on, and in 1949 civil attendances numbered 100,000 . Established features of the scheme are the follow-up of women and the provision of evening clinics. In the past, cases too often disappeared before completion of treatment. To overcome this, women supervisors have been appointed and additional beds provided; when an outpatient fails to keep an appointment she is contacted by the woman supervisor and persuaded to re-attend. This method has been most successful, and, combined with the propaganda spread by satisfied patients, has resulted in increased attendance and a very considerable increase in the total number of cases dealt with.

The success of the scheme is also due largely to the choice of site of the hospital and clinics. Apart from an outdoor clinic in the dock area, there is a 70-bed hospital with attached clinics in a central poor-class district easily visited by the majority of sufferers. There is no public objection to such an institution. Further expansion is to be provided by the creation of more beds, a further clinic in another part of the town, and a travelling clinic for the rural areas.

A point that should be stressed is the confidential and co-operative nature of the service provided. Compulsion is not practised, as it would defeat its object in an Asian people.

I might add that increase in treatment figures does not in any way mean increase in incidence. Singapore today is in most respects a cleaner port than the average in the East.

In this brief review I have merely tried to show the complexity of the subject, how so many factors alien to the V.D. problem in Great Britain must be taken into account in the tropical dependencies if a successful result is to be attained, and how the superimposition of one civilization on another at a somewhat alarming rate is rendering the solution of the venereal-disease problem ever more difficult. 